\title{
Monitoramento de Longo Prazo e Climatologia de Campos Estratosféricos quando da Ocorrência dos Eventos de Influência do Buraco de Ozônio Antártico sobre o Sul do Brasil
}

\author{
Lucas Vaz Peres ${ }^{1}$ (D), Damaris Kirsch Pinheiro ${ }^{2}$ (D), Luiz Angelo Steffenel ${ }^{3}$ (D), David Mendes ${ }^{4}$ (D), \\ José Valentin Bageston $^{5}$ (D), Gabriela Dornelles Bittencourt ${ }^{2}$ (D), André Passáglia Schuch ${ }^{2}$, \\ Vagner Anabor ${ }^{2}$, Neusa Maria Paes Leme ${ }^{6}$ (D), Nelson Jorge Schuch ${ }^{5}$ (D), Hassan Bencherif ${ }^{7}$ \\ ${ }^{1}$ Instituto de Engenharia e Geociências, Universidade Federal do Oeste do Pará, \\ Santarém, PA, Brasil. \\ ${ }^{2}$ Centro de Tecnologia, Universidade Federal de Santa Maria, Santa Maria, RS, Brasil. \\ ${ }^{3}$ Centre de Recherche en STIC, Université de Reims Champagne-Ardenne, Reims, France. \\ ${ }^{4}$ Departamento de Ciências Atmosféricas e Climáticas, \\ Universidade Federal do Rio Grande do Norte, Natal, RN, Brasil. \\ ${ }^{5}$ Centro Regional Sul de Pesquisas Espaciais, Instituto Nacional de Pesquisas Espaciais, \\ Santa Maria, RS, Brasil. \\ ${ }^{6}$ Centro Regional do Nordeste, Instituto Nacional de Pesquisas Espaciais, Natal, RN, Brasil. \\ ${ }^{7}$ Laboratoire de l'Atmosphère et des Cyclones, Université de La Réunion, LACy, UMR 8105, \\ Reunion Island, France.
}

Recebido em: 10 de Abril de 2017 - Aceito em: 23 de Abril de 2018

\begin{abstract}
Resumo
O monitoramento de longo prazo dos eventos de Influência do Buraco de Ozônio Antártico sobre o Sul do Brasil foi realizado no período de 35 anos entre 1979 e 2013 e calculada a climatologia e anomalias dos campos estratosféricos quando de sua ocorrência. Para isso, foram analisados os dados da coluna total de ozônio (CTO) obtidos através de Espectrofotômetros Brewer, instalados no Observatório Espacial do Sul - OES/CRS/INPE - MCTIC $\left(29,4{ }^{\circ} \mathrm{S} ; 53,8{ }^{\circ} \mathrm{O}\right.$; 488,7 m) e pelos instrumentos de satélite Total Ozone Mapping Spectrometer (TOMS) e Ozone Monitoring Instrument (OMI), além de parâmetros da reanálise II do NCEP/DOE (National Centers for Environmental Prediction/ Departament of Energy) e trajetórias retroativas do modelo HYSPLIT (HYbrid Single-Particle Lagrangian Integrated Trajectory). A metodologia empregada mostrou-se eficaz na identificação de 62 eventos com uma redução média de $-9,35 \pm$ $2,93 \%$ no conteúdo de ozônio. Além disso, foi realizada a identificação do padrão de circulação estratosférica através de campos médios e anomalias da vorticidade potencial, vento e temperatura para os dias de ocorrência do fenômeno, sendo observado um padrão de deslocamento de onda, embebida dentro de uma ampla região de circulação ciclônica, com ventos predominantemente de sul é advectado em direção ao Sul do Brasil.
\end{abstract}

Palavras-chave: influência do buraco de ozônio Antártico, climatologia e estratosfera.

\section{Long Term Monitoring and Climatology of Stratospheric Fields when the Occurrence of Influence of the Antarctic Ozone Hole Over South of Brazil Events}

\begin{abstract}
The long-term monitoring of Influence of the Antarctic Ozone Hole over South of Brazil events was carried out for the period of 35 years between 1979 and 2013 and the climatology and anomalies of the stratospheric fields were calculated
\end{abstract}

Autor de correspondência: Lucas Vaz Peres, lucas.peres@ufopa.edu.br. 
when this type of phenomenon occurred. For this, the data of the total ozone column (TOC) was obtained by Brewer Spectrophotometers, installed at the Southern Space Observatory - SSO / CRS / INPE - MCTIC $\left(29.4{ }^{\circ} \mathrm{S}, 53.8^{\circ} \mathrm{W}, 488\right.$, $7 \mathrm{~m}$ ) and the Total Ozone Mapping Spectrometer (TOMS) and Ozone Monitoring Instrument (OMI) satellite instruments, as well as the reanalysis II of the NCEP / DOE (National Centers for Environmental Prediction / Department of Energy) and retroactive trajectories by HYSPLIT ( HYbrid Single-Particle Lagrangian Integrated Trajectory) model. The methodology used was effective in identifying 62 events with a mean reduction of $-9.35 \pm 2.93 \%$ in the ozone content. In addition, the stratospheric circulation pattern was identified through mean fields and anomalies of potential vorticity, wind and temperature for the occurrence days of the phenomenon, with a wave displacement pattern embedded within a wide cyclonic circulation region, with predominantly southern winds is advected toward the south of Brazil.

Keywords: influence of the Antarctic ozone hole, climatology and stratosphere

\section{Introdução}

O gás ozônio é o principal constituinte traço da estratosfera, sendo, juntamente com o vapor d'água, essencial para a vida e o balanço energético do planeta. Ele possui um papel chave no suporte da vida na superfície terrestre devido a sua capacidade de interceptação da radiação Ultravioleta (UV) nociva aos seres vivos (Salby, 1996).

A descoberta do "Buraco de Ozônio Antártico" (Farman et al., 1985) despertou o interesse da comunidade científica, podendo seus efeitos influenciar diretamente o conteúdo de ozônio de regiões de médias latitudes, devido ao deslocamento da borda do vórtice polar sobre estas regiões (Kirchhoff et al., 1997; Solomon, 1999; Marchand et al., 2005). Indiretamente, o Buraco de Ozônio Antártico pode influenciar o conteúdo de ozônio de regiões de médias e baixas latitudes através do desprendimento filamentos polares (Prather and Jaffe,1990; Waugh, 1993; Manney et al., 1994), transportando massas de ar pobre em ozônio do vórtice polar Antártico, causando uma diminuição temporária na coluna total de ozônio sobre estas regiões.

Como consequência dessas reduções no conteúdo de ozônio são verificados aumentos dos níveis de radiação ultravioleta prejudicial aos seres vivos que chega a superfície (Larry et al., 1995; Casiccia et al., 2008; De Laat et al., 2010), justificando os estudos sobre o tema, uma vez que uma diminuição de $1 \%$ no conteúdo de ozônio pode causar um aumento de $1,2 \%$ da radiação ultravioleta sobre o Sul do Brasil (Guarnieri et al., 2004).

Anomalias extremas no conteúdo total de ozônio em médias latitudes da estratosfera são associadas com o transporte meridional de regiões onde as concentrações climatológicas são mais baixas ou altas (Koch et al., 2002). A passagem de massas de ar, de origem no Buraco de Ozônio Antártico sobre regiões de médias latitudes, foi primeiramente observada sobre o Sul do Brasil $\left(29,4{ }^{\circ} \mathrm{S}\right.$; $53,8^{\circ} \mathrm{W}$ ) por Kirchhoff et al. (1996). Este tipo de fenômeno segue sendo observado sobre a América do Sul (Perez e Jaque, 1998; Perez et al., 2000; Pinheiro et al., 2011; 2012), Sul do continente africano (Semane et al., 2006) e Nova Zelândia (Brinksma et al., 1998).

Estudos recentes (Peres et al., 2016) apontaram a ocorrência de dois eventos de Influência do Buraco de
Ozônio Antártico sobre o Sul do Brasil no ano de 2012, observados no nível isentrópico de $620 \mathrm{~K}$ de temperatura potencial, causando redução média na coluna total de ozônio em relação às médias mensais climatológicas de 12,1 $\pm 2,3 \%$. Já Peres et al. (2014), verificaram a condição sinótica da troposfera destes dois eventos e associaram a passagem de um sistema frontal estacionário, com passagem de áreas de estabilidade, sem nebulosidade significativa, relacionada ao afastamento da corrente de jato subtropical para o oceano atlântico, sobreposta por um amplo sistema de alta pressão. Um dos casos chegou a configurar condição de Bloqueio Atmosférico, sugerindo que quanto mais intensa for a massa de ar estável pósfrontal, maior será a queda no conteúdo de ozônio.

Este padrão é similar ao observado no evento de Influência do Buraco de Ozônio Antártico ocorrido sobre o Sul do Brasil no dia 14 de outubro de 2008 observado por Peres et al. (2011). Além disso, Steffenel et al. (2016) utilizou ambiente de Computação Pervasiva para detectar eficazmente a ocorrência deste tipo de evento em 22 de outubro de 2013. Esta iniciativa foi tomada no sentido de ajudar a realizar alertas à população e as autoridades locais sobre os futuros aumentos da radiação UV. Radiação esta que vem auxiliando na explicação do declínio de espécies de anfíbios sobre a região sul do Brasil (Schuch et al., 2015).

Randel e Wu (1996) caracterizaram a variabilidade do conteúdo de ozônio em escala climática, ao analisar a influência da oscilação quase-bienal (QBO) sobre o conteúdo de ozônio, utilizando a técnica de decomposição em valores singulares. Xie et al. (2014) utilizaram métodos estatísticos como composições médias, anomalias em relação a média e Análise de Componentes Principais (ACP) a fim de relacionar a ocorrência do fenômeno climático El Niño Modoki com a variabilidade no conteúdo global de ozônio.

A aplicação destas técnicas estatísticas em variáveis meteorológicas na caracterização da circulação atmosférica durante a ocorrência de diferentes modos de variabilidade que regem a precipitação sobre a América do Sul (Liebmann et al., 1999), motivaram as iniciativas de caracterização da dinâmica de circulação estratosférica quando da ocorrência de eventos de Influência do Buraco de Ozônio Antártico sobre o Sul do Brasil. Em vista destas 
iniciativas de estudos sobre observação e entendimento climatológico do conteúdo de ozônio em escala global e regional, o presente artigo busca realizar a identificação de longo prazo dos eventos de Influência do Buraco de Ozônio Antártico sobre o Sul do Brasil e o entendimento do comportamento sazonal e anomalias dos campos estratosféricos quando da ocorrência deste tipo de eventos no período de trinta e cinco anos entre 1979 e 2013.

\section{Material e Métodos}

O monitoramento da coluna total de ozônio sobre o Sul do Brasil é realizado através dos dados da coluna total de ozônio obtido através dos Espectrofotômetros Brewer modelo MKIV \#081 durante o período de 1992 - 2000, modelo MKII \#056 de 2000 - 2002 e modelo MKIII \#167 de 2002 até o momento, instalados no Observatório Espacial do Sul - OES/CRS/INPE - MCTI $\left(29,4{ }^{\circ} \mathrm{S} ; 53,8^{\circ} \mathrm{O}\right.$; 488,7m), em São Martinho da Serra, Rio Grande do Sul, Brasil (Schuch et al., 1997), apresentado na Fig. 1, a partir de um convênio entre a Universidade Federal de Santa Maria (UFSM) e o Instituto Nacional de Pesquisas Espaciais (INPE/MCTI). Os Espectrofotômetros Brewer que operam no OES desde 1992 até o presente, pertencem à rede Brasileira de Brewers e recebem testes da Lâmpada Padrão (SL), lâmpada de Mercury $(\mathrm{Hg})$, do motor do obturador Run/Stop (RS) e Tempo de morte da fotomultiplicadora (DT), acompanhados diariamente e os testes UV com as lâmpadas externas realizados mensalmente, enquanto o Teste de Varredura é realizado ocasionalmente de acordo com as recomendações do fabricante (SCI-TEC, 1988). Peres et al., 2017 analisou o monitoramento de longo prazo da coluna total de ozônio a partir destes equipamentos, explicando os problemas técnicos que ocasionaram as falhas observadas na série de dados e as substituições de equipamentos ocorridos durante o período. Além disso, encontrou bom acordo com medidas de instrumentos de satélite TOMS (instrumentos Total Ozone Mapping Spectrometer) e OMI (Ozone Monitoring Instrument), com diferenças inferiores a 3\%, indicando a acurácia de ambas as séries de dados utilizados nesta análise. Neste estudo também são utilizados dados obtidos pelos TOMS, da National Aeronautics and Space Agency (NASA) e OMI, do Programa Aeroespacial da Netherlands's Agency (NIVR) em colaboração com o Finnish Meteorological Institute (FMI) para a Missão Aura EOS. Ambos dados de satélites são coletados para a mesma localização do Observatório Espacial do Sul.
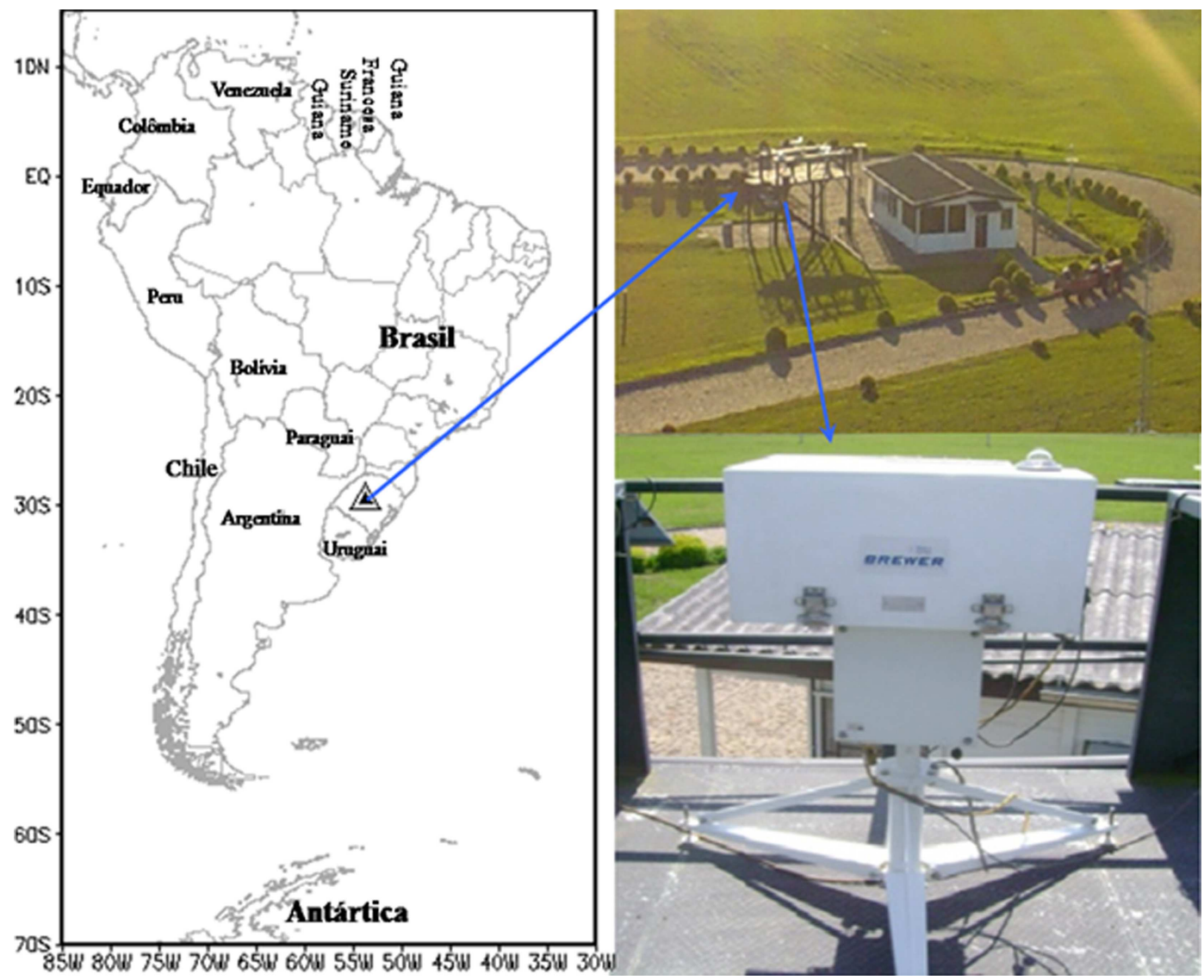

Fig. 1: - Prédio 1 do Observatório Espacial do Sul - OES/CRS/INPE - MCTI em São Martinho da Serra $\left(29,42^{\circ} \mathrm{S}, 53,87^{\circ} \mathrm{O}\right)$, Rio Grande do Sul, Brasil e o Espectrofotometro Brewer \#167. 
O Espectrofotômetro Brewer é um instrumento instalado no solo, totalmente automatizado que efetua medidas da radiação solar global na banda de Ultravioleta do tipo B - UVB em cinco comprimentos de onda 306,3; 310,$1 ; 313,5 ; 316,8 ; 320,1 \mathrm{~nm}$, com resolução aproximada de $0,5 \mathrm{~nm}$ e permite a dedução da coluna total dos seguintes gases atmosféricos: ozônio (O3), dióxido de enxofre (SO2) e dióxido de nitrogênio (NO2), podendo também obter o perfil vertical de $\mathrm{O} 3$ pela técnica de Umkehr e as quantidades de NO2 estratosférico e troposférico pela técnica de Twilight (Kerr et al., 1985; Kerr, 2002). O instrumento Brewer \#167, atualmente localizado no Observatório Espacial do Sul, pertence à rede Brasileira de Brewer, recebendo checagens e testes diários, semanais e mensais, além de ser bianualmente calibrado por comparação com o instrumento padrão de referência Brewer \#017 pertencente à empresa International Ozone Services Inc., que presta os serviços de calibração na América do Sul, garantindo qualidade nos dados da coluna total de ozônio (WMO, 1996).

A aquisição dos dados de satélite para esta análise foi realizada através do TOMS, que foi um instrumento desenvolvido pela National Aeronautics and Space Agency (NASA) e mediu ozônio diariamente fornecendo mapas globais de alta resolução de ozônio total contido na atmosfera. Esse instrumento existiu de 1978 a 2005, iniciando suas medidas com o lançamento do satélite Nimbus-7, continuando de 1991 a 1994 a bordo do satélite Meteor-3 e desde 1996 a bordo do Earth Probe, parando de operar no final de 2005 devido a problemas de calibração. O TOMS utiliza a técnica Backscatter Ultraviolet (BUV), um método de medida que determina ozônio indiretamente pelo mapeamento da luz ultravioleta emitida pelo Sol e retroespalhada pela atmosfera terrestre na direção do satélite. O TOMS faz amostragem da radiação UV retroespalhada em seis comprimentos de onda, que sofrem absorção diferencial pelo ozônio. Comparando essas medidas entre si com as medidas provenientes do Sol, o algoritmo do TOMS calcula a coluna total de ozônio (McPeters et al., 1996; Herman et al., 1996; McPeters et al., 1998).

No final do ano de 2005, o equipamento TOMS parou de realizar suas medidas, passando a ser disponibilizados no site da NASA dados do OMI. Este equipamento opera desde agosto de 2004 a bordo do satélite ERS-2. O equipamento mede outros componentes atmosféricos que o TOMS, como o conteúdo total de $\mathrm{O} 3, \mathrm{NO} 2$, $\mathrm{SO} 2$ e aerossóis (ATBD-OMI-01, 2002). Assim como o TOMS, o OMI realiza medidas pela técnica Backscatter Ultraviolet (BUV), com duas imagens alimentando a grade do espectrômetro. Tem duas faixas de ultravioleta: UV-1, 270 a 314 nm e UV-2 306 a $380 \mathrm{~nm}$ com resolução espectral de $1-0,45 \mathrm{~nm}$.

A fim de monitorar a ocorrência de eventos de Influência do Buraco de Ozônio Antártico sobre o Sul do Brasil, foram selecionadas datas de redução na CTO abaixo do limite climatologia mensal menos 1,5 desvio padrão ( $\mu \mathrm{i}-1,5 \sigma \mathrm{i})$ nos valores da CTO durante os meses de atuação do Buraco de Ozônio Antártico, na primavera austral, entre os meses de agosto e novembro, de maneira similar ao realizado por Pinheiro et al., 2011 e Peres et al., 2016.

Para os dias de redução na CTO, à origem polar das massas de ar foi verificada através campos de Vorticidade Potencial (PV) na superfície isentrópica de 620 Kelvin de temperatura potencial, representando a altura da máxima concentração de ozônio na estratosfera, ou seja, 24 km de altitude (London, 1985), gerados a partir de parâmetros das componentes meridional (v-wind) e zonal (u-wind) do vento e de temperatura para os níveis de pressão 1000 , $925,850,700,600,500,400,300,250,200,150,100,70$, $50,30,20,10 \mathrm{hPa}$, fornecidos pelo fornecidos pela reanálise II do NCEP/DOE (National Centers for Environmental Prediction/ Departament of Energy), 2,5 $5^{\circ}$ x 2,5 de latitude / longitude, disponíveis em https://www.esrl.noaa. gov/psd/data/gridded/data.ncep.reanalysis2.html (Kanamitsu et al., 2002). A variação da vorticidade potencial em superfície isentrópica pode ser aplicada ao transporte de ozônio na estratosfera, mostrando que a origem tropical ou polar das massas de ar pobre em ozônio pode ser identificada, respectivamente, por menores e maiores valores de vorticidade potencial absoluta (Semane et al., 2006).

Também são confeccionadas trajetórias retroativas das massas de ar pelo modelo HYSPLIT (HYbrid SingleParticle Lagrangian Integrated Trajectory), da National Oceanic and Atmospheric Administration (NOAA), disponível em http://ready.arl.noaa.gov/HYSPLIT.php (Gupta et. al., 2007), em 20, 24 e $28 \mathrm{~km}$ de altura, realizada para seis dias anteriores à ocorrência do evento, e analisadas imagens de conteúdo de ozônio dos instrumentos de satélite TOMS e OMI da NASA, disponíveis em http://ozoneaq.gsfc.nasa.gov/, com a finalidade de confirmar a origem polar da massa de ar estratosférica, verificando a atuação do Buraco de Ozônio na região Antártica e a existência de conexão com o Sul do Brasil, através da ejeção de massas de ar pobre em ozônio para fora do vórtice polar Antártico, de maneira similar a realizada por Pinheiro et al. (2011 e 2012) e Peres et al. (2016).

A partir da identificação das datas de ocorrência dos eventos de Influência do Buraco de Ozônio Antártico sobre o Sul do Brasil entre o período de 35 anos entre 1979 e 2013, observou-se a necessidade de entender os padrões climatológicos sazonal de circulação da estratosfera durante a ocorrência deste tipo de fenômeno. Com o objetivo de identificar os padrões médios e as anomalias em relação à climatologia normal da região dos eventos de influência do Buraco de Ozônio Antártico sobre o Sul do Brasil entre 1979 e 2013, os conjuntos de dados foram manipulados de maneira a organizá-los em matrizes de valores de médias diárias de cada uma das variáveis (temperatura, u, v), em uma grade de $2,5^{\circ}$ de latitude por $2,5^{\circ}$ de longitude, 17 níveis na vertical, e tempo de 12784 dias. 
A manipulação do conjunto de dados permitiu a sua separação em meses e posterior cálculo das médias climatológicas mensais, para cada uma das variáveis mencionadas em seus 17 níveis.

Além disso, as datas de ocorrência dos eventos de influência do Buraco de Ozônio Antártico sobre o Sul do Brasil para os trinta e cinco anos de análise foram separadas em uma matriz $[\mathrm{X}]$ de $\mathrm{n}$ tempos (numero de eventos observados), dada pela Eq. (1), e posterior cálculo de sua média, Eq. (2), e da anomalia, Eq. (3), em relação à média das climatologias mensais entre agosto e novembro, meses de ocorrência do evento.

$$
\begin{gathered}
X=\left[\begin{array}{l}
x_{11} x_{12} \ldots x_{1 p} \\
x_{21} x_{22} \ldots x_{2 p} \\
\cdot \\
x_{n 1} x_{n 2} \ldots x_{n p}
\end{array}\right] \\
\overline{X_{n}}=\frac{1}{n} \sum_{i=1}^{n} X \\
X^{\prime}=X-\bar{X}_{n}
\end{gathered}
$$

O objetivo desta análise é salientar o padrão médio reinante de circulação da estratosfera durante a ocorrência dos eventos de Influência do Buraco de Ozônio Antártico sobre o sul do Brasil.

\section{Resultados e Discussão}

\subsection{Observação dos eventos de influência do buraco de ozônio antártico sobre o sul do Brasil entre 1979 e 2013}

A Fig. 2 apresenta o diagrama esquemático das séries temporais da CTO para cada um dos instrumentos de solo (a), satélites TOMS (b) e OMI (c) e a série mesclada usando dados de Brewer e na sua falta dados de satélite (d), usadas no monitoramento da CTO sobre o Observatório Espacial Sul entre 1979 e 2013, onde dos 12784 dias que compreendem o período entre janeiro de 1979 e dezembro de 2013, 30923 foram preenchidos por observações de Espectrofotômetro Brewer, o qual entrou em operação no OES a partir de 1992. Nota-se um ciclo anual bem definido em todos os conjuntos de dados e períodos de ausência de dados nos registros de Espectrofotômetro Brewer entre 1999 e 2000 e 2009 e 2011 e nos registros de satélite TOMS entre 1994 e 1996.

Peres et al. 2017 realizou uma profunda análise de comparação diária e mensal destes conjuntos de dados, revelando um elevado grau de proporcionalidade entre Brewer e satélites TOMS e OMI, devido aos altos valores de $\mathrm{R}^{2}(0,88$ e 0,93$)$, respectivamente. Estas observações são semelhantes às observadas por Viatte et al. (2011) sobre as Ilhas Canárias, Antón et al. (2009; 2010 (a) e 2010 (b)) na Espanha, além de Roma na Itália (Ialongo et al., 2008) e outras estações de monitoramento de ozônio ao redor do planeta (Keckhut et al., 2010; Hendrick et al.,
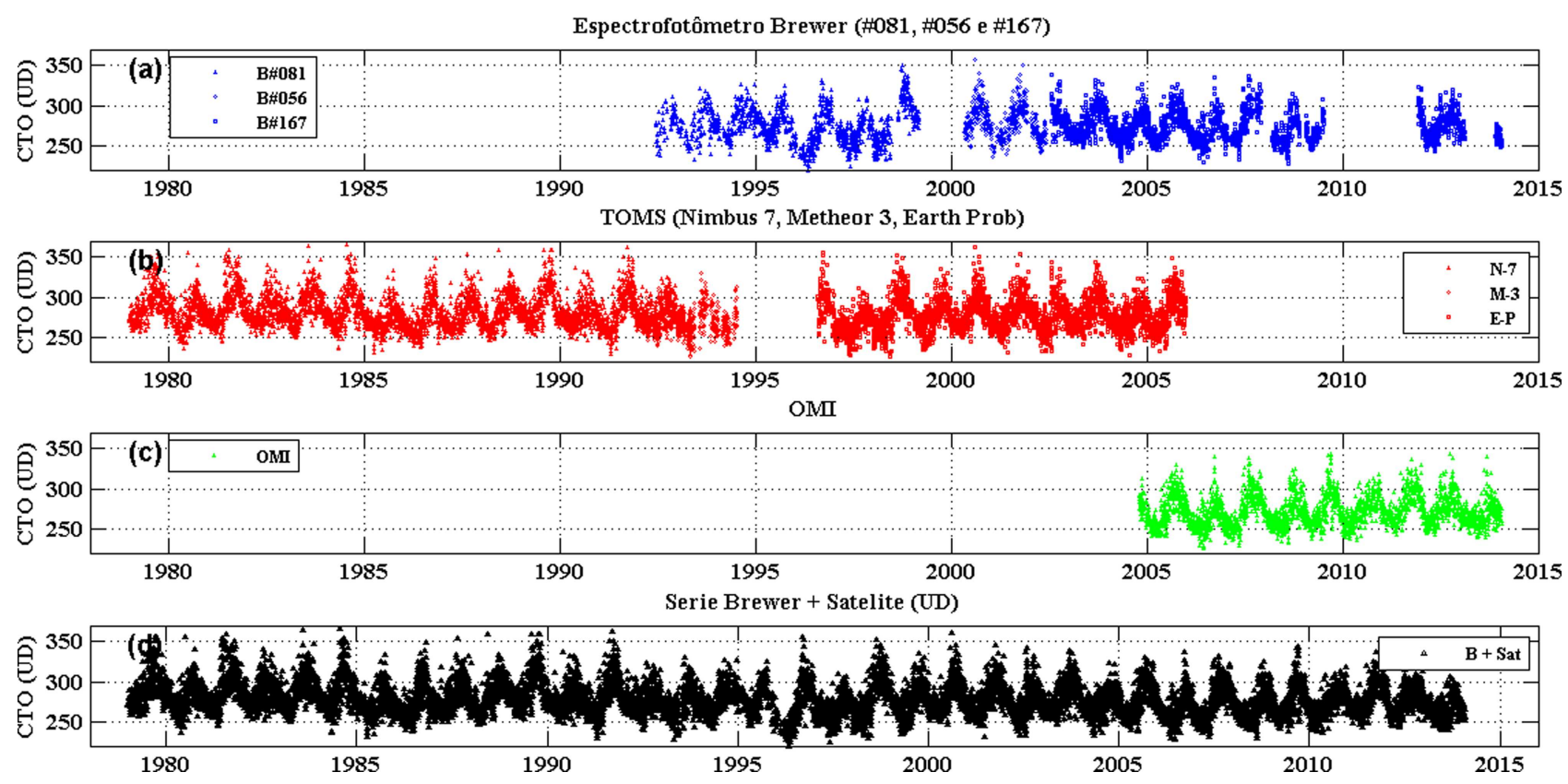

Fig. 2: - Séries temporais da média diária da CTO para cada instrumento (Brewer e satélite) no Observatório Espacial do Sul (OES) entre 1979 e 2013 . (a) Espectrofotômetro Brewer (\# 081 em triângulo, \# 056 em círculo e \# 167 em quadrado), (b) instrumentos de satélite TOMS (Nimbus-7 em triangulo, Meteoro-3 em circulo e Earth Prob em quadrado) e OMI em triangulo verde (c), além da série mesclada Brewer mais satélite TOMS e OMI em triangulo preto (d). 
2011), o que possibilita a mescla destes conjuntos de dados a fim de preencher a série com o maior numero dias disponíveis como realizado na Fig. 2 (d).

Após a verificação da série de dados mesclada (Fig. 2d) de monitoramento de conteúdo de ozônio, entre os meses de agosto e novembro, devido à natureza de ocorrência do Buraco de Ozônio (Solomon, 1999), foram calculados os valores climatológicos mensais e seus respectivos desvios padrões e valor limite de média climatológica menos 1,5 desvios padrão $(\mu \mathrm{i}-1,5 \sigma \mathrm{i})$ de seu respectivo mês, para os dias de redução na coluna de ozônio entre os 1979 e 2013 apresentados na Tabela 1.
Demostrando a metodologia aplicada na identificação de ocorrência deste tipo de fenômeno, a Fig. 3 apresenta a dinâmica de circulação característica da estratosfera ocorrida durante o evento de Influência do Buraco de Ozônio Antártico sobre o Sul do Brasil do dia 14 de setembro de 2012, analisado por Peres et al. (2016), onde a coluna total de ozônio alcançou 267,8 UD, representando uma redução de $9,7 \%$ em relação à média climatológica do mês de setembro, 296,5 \pm 9,9 UD, sendo este estudo de caso considerado como evento característico para esta análise, vindo a ser tomado por base em análises futuras.

Tabela 1: - Valores climatológicos mensais, desvio padrão e limite -1,5 $\sigma$ para Agosto, Setembro, Outubro e Novembro no OES.

\begin{tabular}{lccc}
\hline Mês & Climatologia (UD) & DP (UD) & $-1.5 \sigma(U D)$ \\
\hline Agosto & 284,9 & 9,1 & 271,3 \\
Setembro & 296,5 & 9,9 & 281,6 \\
Outubro & 290,2 & 8,8 & 277,0 \\
Novembro & 286,5 & 13,0 & 267,0 \\
\hline
\end{tabular}

Potencial Vorticity, 13/SEP/2012, 620k
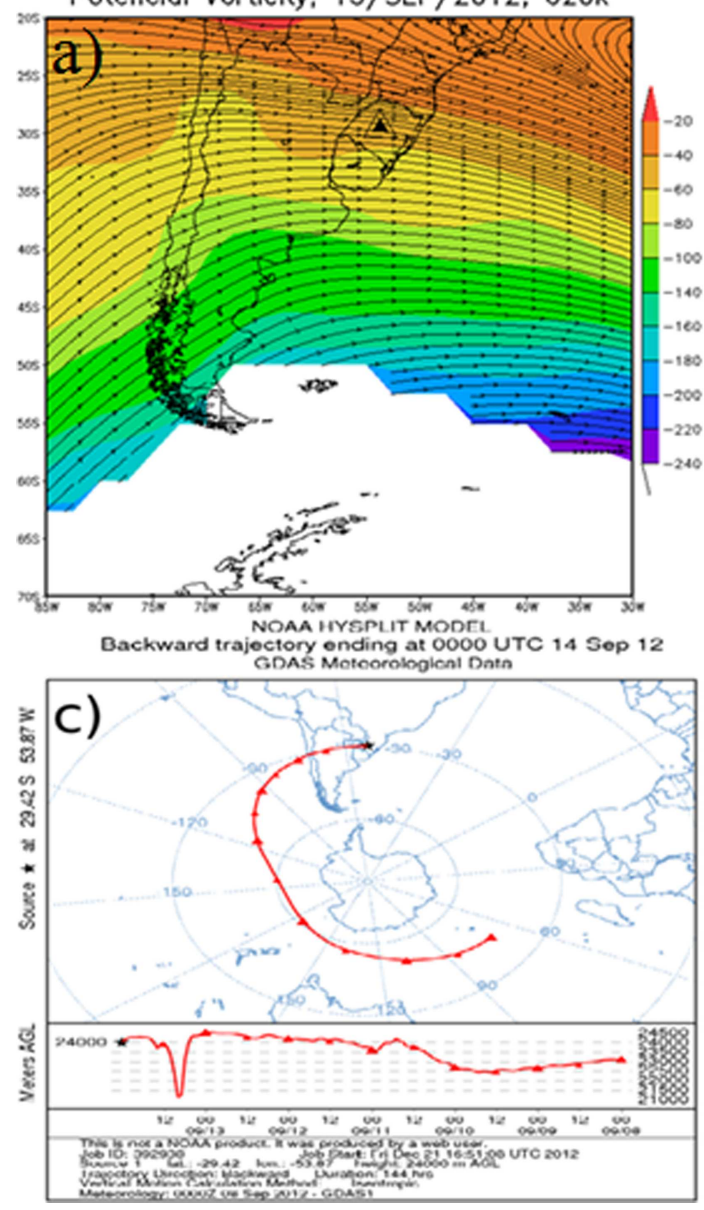

Potencial Vorticity, 14/SEP/2012, 620k

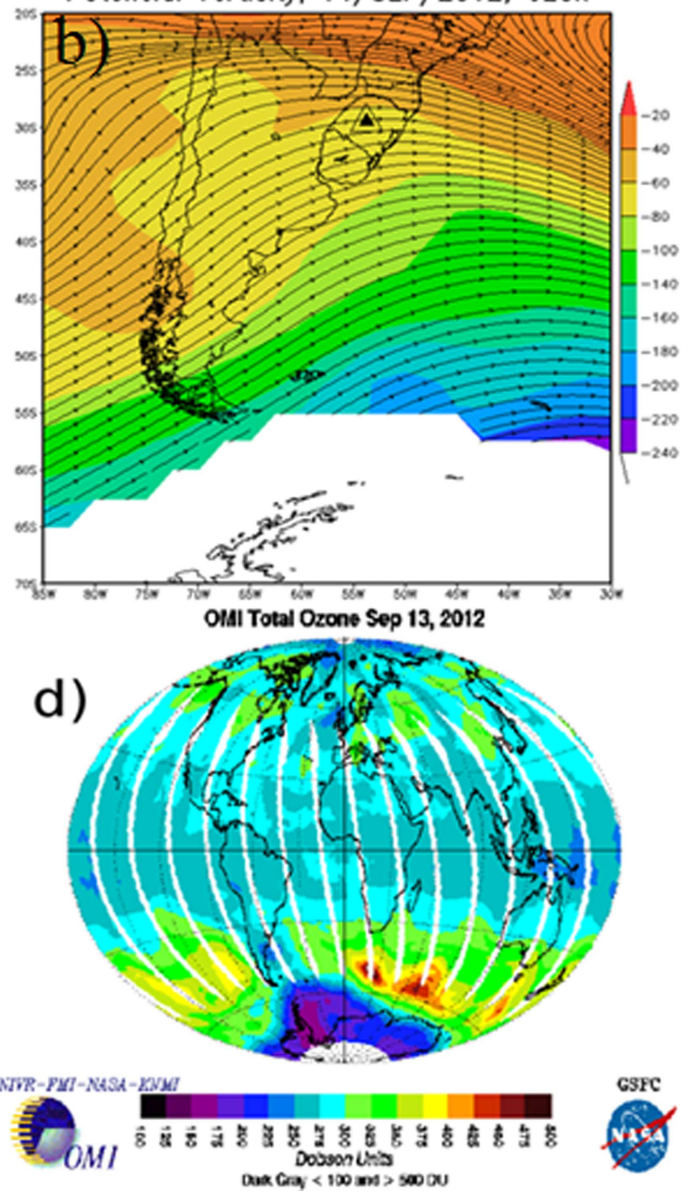

Fig. 3: - Vorticidade Potencial e vento para 13 (a) e 14 (b) de setembro a 620K, trajetória retroativa do modelo Hysplit da NOAA em 24 km de altura para 14 de setembro imagem do satélite OMI (c) para 13 de setembro de 2012. Fonte: Adaptado de Peres et al., 2016. 
Foi observado, através dos mapas de vorticidade potencial no nível isentrópico de $620 \mathrm{~K}$ de temperatura potencial, que uma massa de ar com maiores valores de vorticidade potencial absoluta se deslocou do centro-norte da Argentina e Uruguai no dia 13 de setembro (a), envolta em uma circulação ciclônica com ventos predominantemente de Sul, e atingiu o Sul do Brasil no dia 14 de setembro de 2012 (b). A trajetória retroativa da massa de ar, confeccionada pelo modelo Hysplit da NOAA, do dia 14 de setembro (c), e a imagem do conteúdo de ozônio do satélite OMI, do dia 13 de setembro (d), complementam a análise, evidenciando a origem polar da massa de ar e a conexão entre a região Antártica com o Sul do Brasil durante o evento que ocasionou a queda temporária na coluna de ozônio, confirmando a ocorrência do evento de Influência do Buraco de Ozônio Antártico sobre o Sul do Brasil do dia 14 de setembro de 2012.

Utilizando esta mesma metodologia, foram identificados 62 eventos deste tipo no período entre os anos de 1979 e 2013, com porcentagem média de queda na coluna total de ozônio de 9,35 2,93\%, apresentados na Tabela 2 .

Complementando os resultados obtidos por Peres (2013), foi observada a ocorrência de oito eventos durante o mês de agosto, ou seja, $12,9 \%$ dos eventos, dezenove eventos no mês de setembro, ou seja, 30,6\% dos eventos. A maior parte dos eventos, em vinte e oito, ocorreram no mês de outubro, ou seja, $45,1 \%$ dos eventos, restando apenas $11,2 \%$ dos eventos no mês de novembro com a ocorrência de sete eventos.

\subsection{Identificação do padrão médio de circulação estratosférica dos eventos de influência do buraco de ozônio antártico sobre o sul do Brasil}

As médias climatológicas mensais de temperatura e das componentes $\mathrm{u}$ e $\mathrm{v}$ do vento foram calculadas para os 17 níveis de altura disponíveis para este conjunto de dados da reanálise II do NCEP/DOE, sendo possível representar dessa maneira a característica sazonal climatológica destas variáveis em cada um de seus níveis. A partir da climatologia mensal destas três variáveis, foi calculada a climatologia mensal de vorticidade potencial e vento para o nível isentrópico de $620 \mathrm{~K}$ de temperatura potencial, apresentada na Fig. 4 para os meses de agosto (a), setembro (b), outubro (c) e novembro (d).

A partir da obtenção das datas de ocorrência de eventos de Influência do Buraco de Ozônio Antártico sobre o Sul do Brasil, os conjuntos de dados foram separados nestas 62 datas e calculados as médias para os 17 níveis de altura das três variáveis meteorológicas mencionadas. Isso possibilitou o cálculo do campo médio da vorticidade potencial e vento para o nível isentrópico de $620 \mathrm{~K}$ de temperatura potencial para os 62 eventos (Fig. 5), desde dois dias antes (a), um dia antes (b), o dia

Tabela 2: - Valor da CTO e seu percentual de redução para as datas de eventos de Influência do Buraco do Ozônio Antártico sobre o Sul do Brasil entre 1979 e 2013.

\begin{tabular}{|c|c|c|c|c|c|c|c|c|}
\hline Evento & O3 (UD) & Red (\%) & Evento & O3 (UD) & Red (\%) & Evento & O3 (UD) & $\operatorname{Red}(\%)$ \\
\hline $12 / 10 / 82$ & 271,4 & $-7,3$ & $16 / 10 / 97$ & 265,1 & $-9,4$ & $13 / 10 / 06$ & 276,4 & $-5,6$ \\
\hline $21 / 10 / 82$ & 261,7 & $-10,6$ & $02 / 11 / 97$ & 267,9 & $-6,8$ & $28 / 10 / 06$ & 259,1 & $-11,5$ \\
\hline $23 / 09 / 82$ & 278,2 & $-6,9$ & 19/11/97 & 266,4 & $-7,3$ & 19/11/06 & 271.9 & $-5,4$ \\
\hline $30 / 09 / 83$ & 273,4 & $-8,5$ & $24 / 10 / 98$ & 260,0 & $-11,2$ & $13 / 09 / 07$ & 274.9 & $-8,0$ \\
\hline $16 / 10 / 84$ & 262,6 & $-10,3$ & 26/08/99 & 270,3 & $-7,6$ & 07/10/07 & 259.5 & $-11,4$ \\
\hline $14 / 09 / 85$ & 273,0 & $-8,6$ & $23 / 09 / 00$ & 270,1 & $-9,6$ & $28 / 09 / 08$ & 275.2 & $-7,9$ \\
\hline $15 / 10 / 85$ & 258,3 & $-11,8$ & 09/10/00 & 276,0 & $-5,7$ & $12 / 10 / 08$ & 267.8 & $-8,5$ \\
\hline $07 / 11 / 85$ & 263,4 & $-8,4$ & $26 / 10 / 00$ & 269,5 & $-7,9$ & $25 / 10 / 08$ & 259.5 & $-11,4$ \\
\hline $27 / 11 / 85$ & 264,1 & $-8,1$ & 07/11/00 & 262,8 & $-8,6$ & 01/11/08 & 252.1 & $-12,3$ \\
\hline $12 / 09 / 86$ & 270,5 & $-9,5$ & $23 / 09 / 01$ & 274,0 & $-8,3$ & 03/09/09 & 256.3 & $-14,2$ \\
\hline 06/09/90 & 246,9 & $-17,4$ & $18 / 08 / 02$ & 254,2 & $-13,0$ & 29/09/09 & 270.2 & $-9,6$ \\
\hline $17 / 09 / 90$ & 268,3 & $-10,2$ & $15 / 10 / 03$ & 270,6 & $-7,5$ & 08/08/10 & 271.2 & $-7,2$ \\
\hline 08/10/90 & 261,0 & $-10,8$ & $22 / 08 / 04$ & 263,5 & $-9,9$ & $13 / 10 / 10$ & 276.2 & $-5,7$ \\
\hline $10 / 10 / 92$ & 267,2 & $-8,7$ & $12 / 09 / 04$ & 276,4 & $-7,5$ & $22 / 10 / 10$ & 261.7 & $-10,6$ \\
\hline $26 / 08 / 93$ & 267,5 & $-8,5$ & $26 / 09 / 04$ & 276,3 & $-7,6$ & $14 / 09 / 12$ & 267.8 & $-10,4$ \\
\hline $31 / 10 / 93$ & 240,4 & $-17,9$ & 03/10/04 & 275,6 & $-5,8$ & $14 / 10 / 12$ & 252.6 & $-13,7$ \\
\hline $17 / 09 / 94$ & 278,5 & $-6,8$ & $16 / 10 / 04$ & 253,6 & $-13,4$ & $20 / 08 / 13$ & 260.0 & $-10,9$ \\
\hline $26 / 10 / 94$ & 274,5 & $-6,2$ & $29 / 09 / 05$ & 280,6 & $-6,1$ & $06 / 09 / 13$ & 274.0 & $-8,2$ \\
\hline $18 / 08 / 97$ & 242,6 & $-17,0$ & $11 / 10 / 05$ & 274,0 & $-6,4$ & $03 / 10 / 13$ & 273.6 & $-6,4$ \\
\hline $14 / 09 / 97$ & 255,0 & $-14,7$ & $20 / 08 / 06$ & 269,7 & $-7,7$ & $22 / 10 / 13$ & 266.9 & $-8,7$ \\
\hline 09/10/97 & 275,5 & $-5,9$ & 07/10/06 & 260,7 & $-10,9$ & \multicolumn{3}{|c|}{ Redução Media: $-9,35 \pm 2,93 \%$} \\
\hline
\end{tabular}



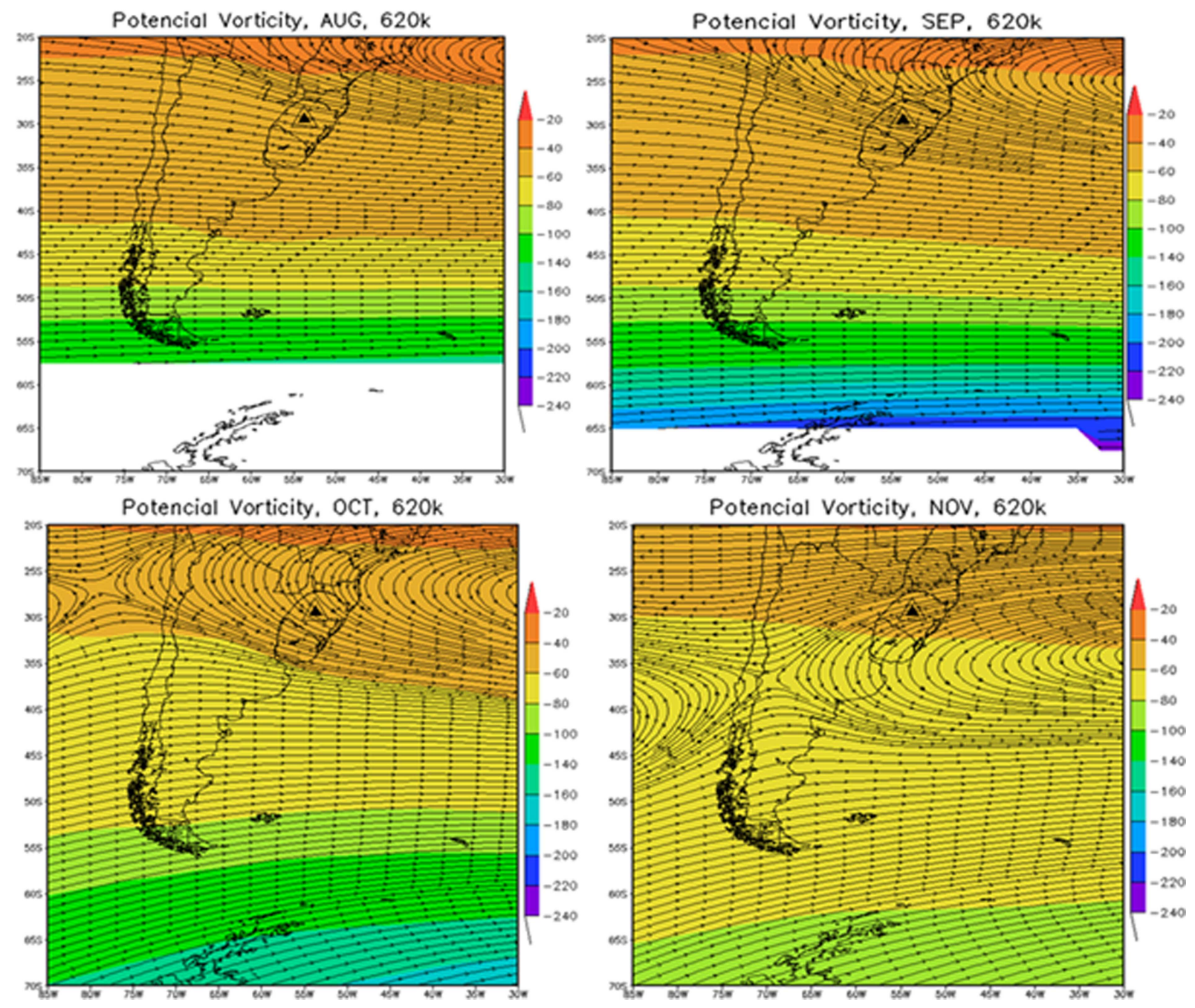

Fig. 4: - Climatologia mensal da Vorticidade Potencial e vento para os meses de agosto (a), setembro (b), outubro (c) e novembro (d) no nível isentrópico de $620 \mathrm{~K}$.

do evento (c) e um dia depois (d). Observa-se claramente a propagação de um distúrbio de onda de escala sinótica nos campos de vorticidade potencial e vento no nível isentrópico de $620 \mathrm{~K}$ de temperatura potencial, evidenciando estes eventos serem uma perturbação do comportamento médio da circulação estratosférica (Canziane et al., 2002), e que o comportamento médio dos eventos é visualmente parecido com o comportamento do evento característico (Fig. 3). Em ambos os casos, evento característico e campos médios dos 62 eventos, é observado um padrão de deslocamento de onda, onde a massa de ar com menores valores de vorticidade potencial (entre 60 e 80 PVU, onde $1 \mathrm{PVU}=10^{-6} \mathrm{~km}^{2} \mathrm{~kg}^{-1} \mathrm{~s}^{-1}$ ) está embebida dentro de uma ampla região de circulação ciclônica, com ventos predominantemente de sul e sendo advectada em direção ao Sul do Brasil.

A partir do cálculo das anomalias dos eventos separados por mês, Fig. 6, em relação a climatologia mensal (Fig. 4) entre os meses de agosto (a), setembro (b), outubro (c) e novembro (d) para o campo de PV em $620 \mathrm{~K}$, foi observando uma ampla região de anomalias negativas de PV atingindo o Sul do Brasil em ambos os meses, evidenciando a atuação de massas de ar de origem polar na baixa estratosfera durante a ocorrência deste tipo de fenômeno. Esta região de anomalia de PV apresenta um comportamento de intensificação a partir de agosto até outubro (mês mais intenso), com sensível enfraquecimento no mês de novembro (mês menos intenso).

A Fig. 7 apresenta uma análise da climatologia dos campos de temperatura no nível de $30 \mathrm{hPa}$, o qual representa o nível de $620 \mathrm{~K}$ de temperatura potencial, sendo exibida a média da climatologia mensal entre agosto e novembro (a), a média para os 62 eventos (b) e a anomalia da média dos 62 eventos em relação à média da climatologia entre os meses de agosto a novembro.

Identifica-se, na média das climatologias mensais, um padrão de dipolo com um núcleo frio sobre o continente Antártico e valores mais elevados nas regiões de 

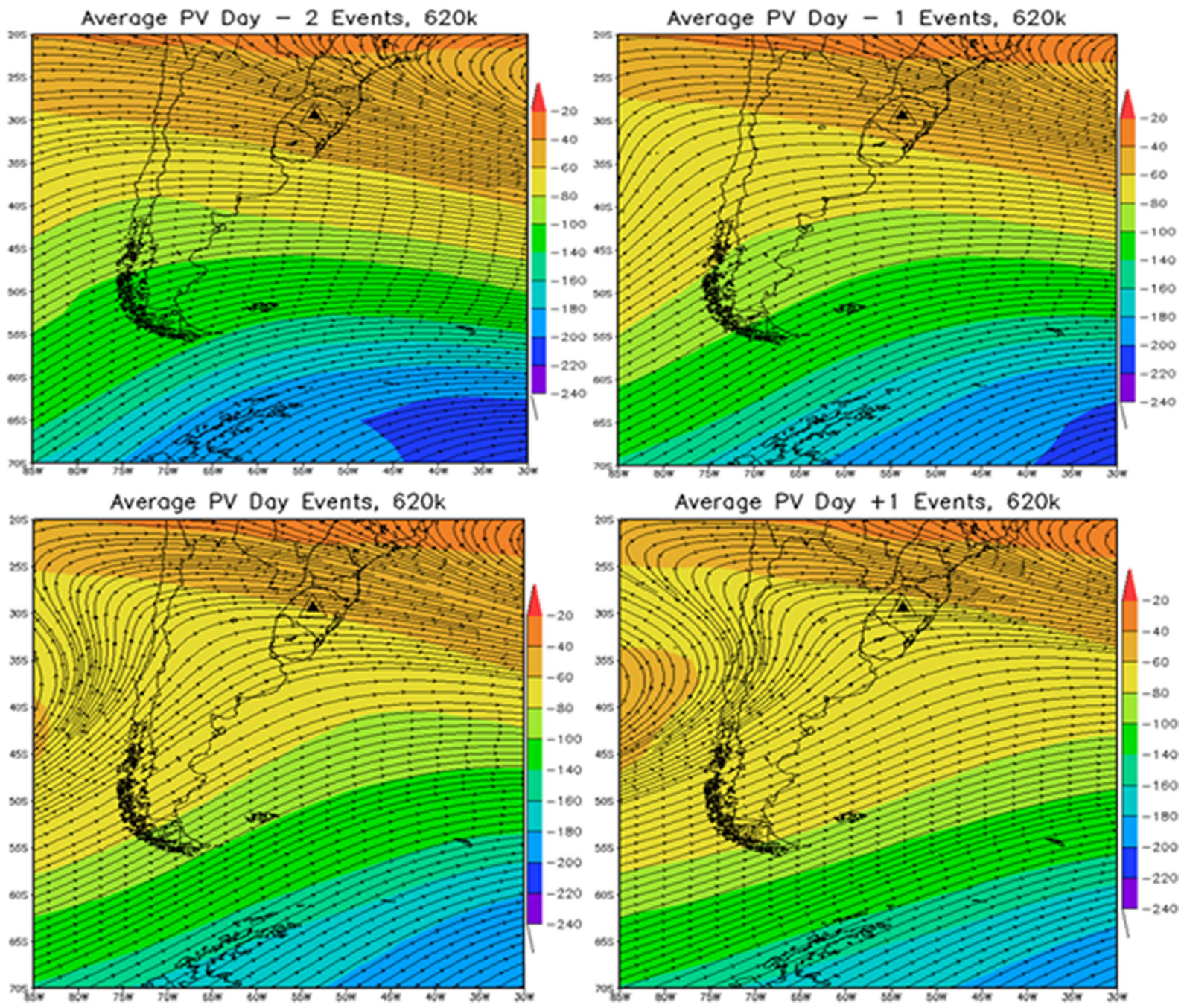

Fig. 5: - Campo médio de vorticidade potencial e vento para (a) dois dias antes, (b) um dia antes, (c) no dia do evento e (d) um dia depois da ocorrência de eventos de Influência do Buraco de Ozônio Antártico sobre o Sul do Brasil entre 1979 e 2013.

médias latitudes (a). Observa-se também o alongamento deste núcleo frio, que atinge o Sul do Brasil na média dos 68 eventos (b), além da observação de uma anomalia negativa de temperatura de $4{ }^{\circ} \mathrm{C}$ sobre o Sul do Brasil e núcleo de $6{ }^{\circ} \mathrm{C}$ sobre o oceano Atlântico Sul e com anomalia positiva de temperatura na região do pacífico sul com núcleo de $6{ }^{\circ} \mathrm{C}$, evidenciando o padrão de dipolo com anomalia negativa sobre o Sul do Brasil na configuração dos campos de temperatura quando da ocorrência deste tipo de fenômeno.

A Fig. 7 também apresenta uma análise da temperatura no nível de $30 \mathrm{hPa}$ durante a ocorrência do evento característico do dia 14 de setembro de 2012, observandose uma lenta propagação de um padrão de onda de anomalia negativa de temperatura de origem polar se deslocando em direção ao sul do Brasil, desde o dia 13 (a), atingindo-o definitivamente no dia 14 (b) e se deslocando em direção ao oceano atlântico no dia 15 (c), padrão semelhante de deslocamento de dipolo de onda de anomalia de temperatura e outras variáveis também estão associados a padrões de precipitação na América do Sul (Liebmann et al., 1999).

\section{Conclusões}

Foi confeccionada uma série de dados da coluna total de ozônio para a região do Observatório Espacial do Sul, no período compreendido entre 1979 e 2013, utilizando prioritariamente dados do espectrofotômetro Brewer e em sua falta com os dados dos sensores TOMS e OMI, sendo calculada sua climatologia mensal, desvios padrões e limite estatístico de média menos 1,5 do seu respectivo desvio padrão ( $\mu \mathrm{i}-1,5 \sigma \mathrm{i})$, especialmente para os meses entre agosto e novembro quando da atuação do fenômeno "Buraco de Ozônio Antártico".

Para os dias de redução na coluna total de ozônio abaixo do limite $-1,5 \sigma$ i foi aplicada a análise de Vorticidade Potencial para a superfície isentrópica de 620 , K de 

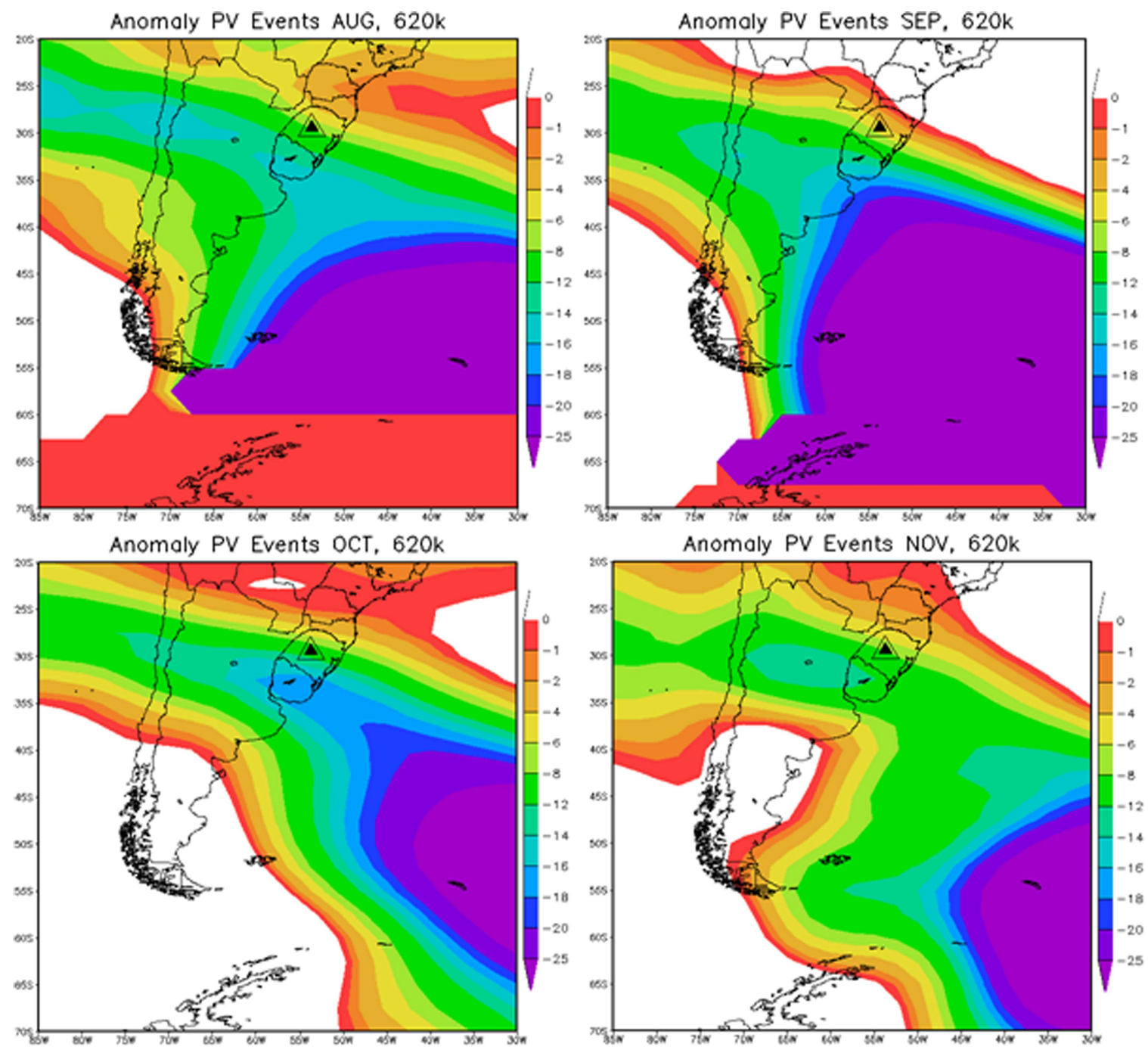

Fig. 6: - Anomalia em relação a climatologia dos Campos de PV em $620 \mathrm{~K}$ durante a ocorrência dos eventos separados por mês entre agosto e novembro.

temperatura potencial $(\sim 24 \mathrm{~km}$ de altura na região de máxima concentração de ozônio na estratosfera), além de serem traçadas as trajetórias retroativas das massas de ar e observadas às imagens de satélite TOMS e OMI, a fim de comprovar a origem polar das massas de ar pobre em ozônio que atingiram o Sul do Brasil. Esta metodologia proporcionou a identificação da ocorrência de sessenta e dois eventos de Influência do Buraco de Ozônio Antártico sobre o Sul do Brasil, no período de 35 anos entre 1979 e 2013 , com redução média de $9,35 \pm 2,93 \%$. Apresentando-se como evento característico o ocorrido em 14 de setembro de 2012, o qual apresentou redução na CTO de $9,7 \%$ em relação a climatologia do mês de setembro, onde uma massa de ar com maiores valores de vorticidade potencial absoluta envolta em uma circulação ciclônica com ventos predominantemente de Sul atingiram o Sul do Brasil na presente data.

Foram calculadas as climatologias mensais para os meses de agosto, setembro, outubro e novembro e a média dos sessenta e dois eventos das variáveis meteorológicas como temperatura e componentes u e v do vento, para os 17 níveis de altura disponíveis no conjunto de dados da reanálise II do NCEP/DOE. Esta análise possibilitou a identificação do padrão climatológico mensal e dos sessenta e dois eventos da vorticidade potencial e vento no nível isentrópico de $620 \mathrm{~K}$ de temperatura potencial, onde se observa, na média dos 62 eventos, desde dois dias antes até um dia depois, que uma massa de ar com menores valores de vorticidade potencial (entre -60 e -80 PVU), embebida dentro de uma ampla região de circulação ciclônica, com ventos predominantemente de sul e sendo advectada de regiões de mais altas latitudes em direção ao Sul do Brasil.

As anomalias dos eventos separados por mês, em relação à climatologia mensal dos campos de $\mathrm{PV}$ em $620 \mathrm{~K}$ foram calculadas, sendo observada uma ampla região de anomalias negativas de PV atingindo o Sul do Brasil em ambos os meses, se intensificando a partir de 


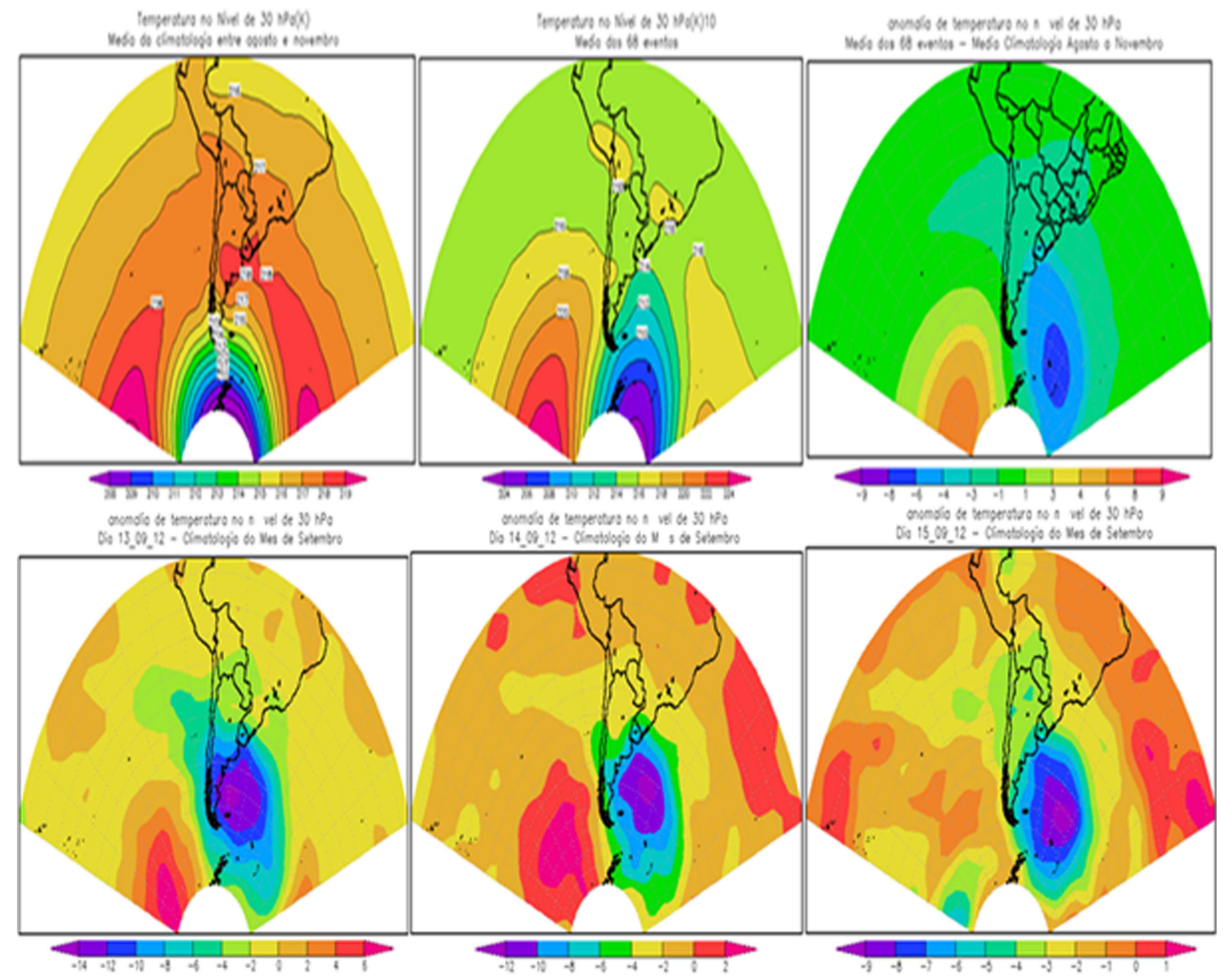

Fig. 7: - Média das Climatologias mensais entre agosto e novembro (a) e média para os 68 dias de evento (b), anomalia dos 68 eventos em relação a média das Climatologias mensais entre agosto e novembro (c), além das anomalias em relação a climatologia do mês de setembro para os dias 13 (d), 14 (e) e 15 (f) de setembro de 2012, para o campo de temperatura em $30 \mathrm{hPa}$.

agosto com 8 PVU, até outubro com 12 PVU, com sensível enfraquecimento no mês de novembro sendo de 6 PVU. O cálculo destes campos médios também possibilitou o cálculo das anomalias da média dos 62 eventos em relação a média das climatologias mensais entre os meses de agosto e novembro para a temperatura no nível de $30 \mathrm{hPa}$, observando-se um padrão de dipolo com uma ampla região de anomalias negativas de temperatura atingindo o Sul do Brasil, evidenciando a atuação de massas de ar de origem polar na baixa estratosfera durante a ocorrência deste tipo de fenômeno.

\section{Agradecimentos}

Este trabalho faz parte do Programa de Pós-Graduação em Meteorologia da Universidade Federal de Santa Maria (UFSM) e do Centro Regional Sul de Pesquisas Espaciais do Instituto Nacional de Pesquisas Espaciais (CRS/CCR/ INPE-MCTIC), apoiado pela Coordenação de Aperfeiçoamento do Pessoal de Ensino Superior (CAPES) Processo n 99999.010629 / 2014-09, do Instituto Nacional de Ciência e Tecnologia - Pesquisa Antártica Ambiental (INCTAPA), que recebe apoio científico e financeiro do Conselho Nacional de Desenvolvimento Científico e Tecnológico 574018 / 2008-5) e Fundação Carlos Chagas Filho para o Apoio à Pesquisa no Estado do Rio de Janeiro (FAPERJ n ${ }^{\circ}$ E-16/170 023/2008) e do Projeto MESO Modelagem e previsão dos Efeitos Secundários do Buraco de Ozônio Antártico (Processo $\mathrm{n}^{\circ}$ 88887.130199/201701) do Programa Capes / Cofecub. Os autores também reconhecem o apoio do Ministério da Ciência, Tecnologia e Inovação (MCTI), do Ministério do Meio Ambiente (MMA) e da Comissão Interministerial de Recursos Marinhos (CIRM), juntamente com a Fundação de Apoio à Pesquisa do Rio Grande do Sul (FAPERGS) por bolsa, índice de clima NASA / TOMS / OMI e NOAA para os dados utilizados na análise, e ao Projeto ATMANTAR, Anúncio do Ano Polar Internacional MCTI / CNPq, Caso No. 52.0182 / 2006-5. 


\section{Referências}

ANTÓN, M.; LÓPEZ, M.; VILAPLANA, J.M.; KROON, M.; MCPETERS, R.; BAÑÓN, M.; AND SERRANO, A. Validation of OMI-TOMS and OMI-DOAS total ozone column using five Brewer Spectroradiometers at the Iberian Peninsula, J. Geophys. Res-Atmos., v. 114, n. D14307, 2009.

ANTÓN, M.; CACHORRO, V.E.; VILAPLANA, J.M.; TOLEDANO, C.; KROTKOV, N.A.; AROLA, A.; SERRANO, A.; DE LA MORENA, B.A. Comparison of UV irradiances from Aura/Ozone Monitoring Instrument (OMI) with Brewer measurements at El Arenosillo (Spain) - Part 1: Analysis of parameter influence, Atmos. Chem. Phys., v. 10, p. 5979-5989, 2010.

ANTÓN, M.; VILAPLANA, J.M.; KROON, M.; SERRANO, A.; PARIAS, M.; CANCILLO, M.L.; DE LA MORENA, B.A. The Empirically Corrected EP-TOMS Total Ozone Data Against Brewer Measurements at El Arenosillo (Southwestern Spain), IEEE Trans. Geosci. Remote Sens., v. 48, n. 7, p. 3039-3045, 2010.

BRINKSMA, E.J.; MEIJER, Y.J.; CONNOR, B.J.; MANNEY, G. L.; BERGWERFF, J.B.; BODEKER, G.E.; BOYD, I.S.; LILEY, J.B.; HOGERVORST, W.; HOVENIER, J.W.; LIVESEY, N.J.; SWART, D.P.J. Analysis of record-low ozone values during the 1997 winter over Lauder, New Zealand. Geophys. Res. Lett., v. 25, n. 15, p. 2785-2788, 1998.

CANZIANI, P.O.; COMPAGNUCCI, R.H.; BISCHOFF, A.S.; LEGNANI, W.E. A study of impacts of tropospheric synoptic processes on the genesis and evolution of extreme total ozone anomalies over southern South America. J. Geophys. Res-Atmos., v. 107, n. D24, p. ACL 2-1-ACL 225, 2002.

CASICCIA, C.; ZAMORANO, F.; HERNANDEZ, A. Erythemal irradiance at the Magellan's region and Antarctic ozone hole 1999-2005. Atmosfera, v. 21 n.1, p. 1-12, 2008.

DE LAAT, A.T.J.; VAN DER, A.R.J.; ALLAART, M.A.F.; VAN WEELE, M.; BENITEZ, G.C.; CASICCIA, C.; LEME, N. M.P.; QUEL, E.; SALVADOR, J.; WOLFRAM, E. Extreme sunbathing: Three weeks of small total O-3 columns and high UV radiation over the southern tip of South America during the 2009 Antarctic O-3 hole season. Geophys. Res. Lett., v. 37, n. L14805, 2010.

FARMAN, J.C.; GARDINER, B.G.; SHANKLIN, J.D. Large losses of total ozone in Antarctica reveal seasonal ClOx/ NOx interaction. Nature. v. 315: p. 207-210, 1985.

GUARNIERI, R.A.; PADILHA, L.F.; GUARNIERI, F.L.; ECHER, E.; MAKITA, K.; PINHEIRO, D.K.; SCHUCH, A.M.P.; BOEIRA, L.S.; SCHUCH, N.J. A study of the anticorrelations between ozone and UV-B radiation using linear and exponential fits in southern Brazil. Adv. Space Res., v. 34, p. 764-768, 2004

GUPTA, S.; LAL, S.; VENKATARAMANI, S.; RAJESH, T.A.; ACHARYA, Y.B. Variability in the vertical distribution of ozone over a subtropical site in India during a winter month, J. Atmos. Terr. Phys., v.69, p.1502-1512, 2007.

HENDRICK, F.; POMMEREAU, J.P.; GOUTAIL, F.; EVANS, R.D.; IONOV, D.; PAZMINO, A.; KYRÖ, E.; HELD, G.; ERIKSEN, P.; DOROKHOV, V.; GIL M.; ROOZENDAEL, M.V. NDACC/SAOZ UV-visible total ozone measurements: improved retrieval and comparison with correlative ground-based and satellite observations, Atmos. Chem. Phys., v. 11, p. 5975-5995, 2011.

HERMAN, J.R.; BHARTIA, P.K.; KRUEGER, A.J.; MCPETERS, R.D.; WELLEMEYER, C.G.; SEFTOR, C. J.; JAROSS, G.; SCHLESINGER, B. M.; TORRES, O.; LABOW, G.; BYERLY, W.; TAYLOR, S.L.; SWISSLER, T.; CEBULA, R.P.; GU, X.Y. Meteor-3 Total Ozone Mapping Spectrometer (TOMS) Data Products User's Guide, NASA, Washington, DC, Tech. Rep. 1996.

IALONGO, I.; CASALE, G.R.; SIANI, A.M. Comparison of total ozone and erythemal UV data from OMI with groundbased measurements at Rome station, ATMOS. CHEM. PHYS., v. 8, p. 3283-3289, 2008.

KANAMITSU, M.; EBISUZAKI, W.; WOOLLEN, J.; YANG, S-K.; HNILO, J.J.; FIORINO, M.; POTTER, G.L. NCEPDOE AMIP-II Reanalysis (R-2). Bulletin of the American Meteorological Society. p. 1631-1643,2002.

KECKHUT, P.; HAUCHECORNE, A.; BLANOT, L.; HOCKE, K.; GODIN-BEEKMANN, S.; BERTAUX, J.L.; BARROT, G.; KYRÖLÄ, E.; VAN GIJSE J.A.E.; PAZMINO, A. Mid-latitude ozone monitoring with the GOMOSENVISAT experiment version 5: the noise issue, Atmos. Chem. Phys., v. 10, p. 11839-11849, 2010.

KERR, J.B.; MCELROY, C.T.; WARDLE, D.I.; OLAFSON, R. A.; EVANS, W.F. The automated Brewer Spectrophotometer, Proceed. Quadr. Ozone Symp. in Halkidiki, C. S. Zerefos and A. Ghazi (Eds.), D. Reidel, Norwell, Mass., p. 396-401, 1985.

KERR, J.B. New methodology for deriving total ozone and other atmospheric variables from Brewer spectrometer direct Sun spectra, J. Geophys. Res., v. 107, n. D23, p. 4731, 2002.

KIRCHHOFF, V.W.J.H.; SCHUCH, N.J.; PINHEIRO, D.K.; HARRIS, J.M. Evidence for an ozone hole perturbation at $30^{\circ}$ south. Atmospheric Environment. v. 30, n. 9, p. 1481$1488,1996$.

KIRCHHOFF, V.W.J.H.; SAHAI, Y.; CASICCIA, C.A.R.; ZAMORANO, F.; VALDERRAMA, V. Observations of the 1995 ozone hole over Punta Arenas, Chile. J. Geophys. Res-Atmos., v. 102, n. D13, p. 16109-16120, 1997.

KOCH, G.; WERNLI, H.; STAEHELIN, J.; PETER, T. A Lagrangian analysis of stratospheric ozone variability and long-term trends above Payerne (Switzerland) during 19702001. J. Geophys. Res., v. 107, n. D19, p. ACL 2-1-ACL 2-14, 2002.

LARY, D.; CHIPPERFILD, M.; PYLE, J.; NORTON, W.; RIISHOJGAARD. L. Treedimensional tracer initialization and general diagnostics using equivalent PV latitudepotential-temperature coordinates, Q. J. Roy. Metror. Soc., v. 121, p. 187- 210, 1995.

LIEBMANN, B.; KILADIS, G.N.; MARENGO, J.A.; AMBRIZZI, T. Submonthly Convective Variability over South America and the South Atlantic Convergence Zone. Journal of Climate, v. 12, p. 1877-1891, 1999.

LONDON, J. Observed distribution of atmospheric ozone and its variations. In: Whitten, R. C., Prasad, S. S. ed. Ozone in the free atmosphere. New York: Van Nostrand Reinhold. cap. 1, p. 11-80, 1985.

MCPETERS, R.D.; BHARTIA, P.K.; KRUEGER, A.J.; HERMAN, J.R.; SCHLESINGER, B.M.; WELLEMEYER, C. G.; SEFTOR, C.J.; JAROSS, G.; TAYLOR, S.L.; 
SWISSLER, T.; TORRES, O.; LABOW, G.; BYERLY, W.; CEBULA R.P. Nimbus-7 Total Ozone Mapping Spectrometer (TOMS) Data Products User's Guide. NASA, Washington, DC, Tech. Rep., 1996.

MCPETERS, R.D.; BHARTIA, P.K.; KRUEGER, A.J.; HERMAN, J.R.; WELLEMEYER, C.G.; SEFLOR, G.; JAROSS, C.F.; TORRES, O.; MOY, L.; ABOW, G.; BYERLY, W.; TAYLOR, S.L.; SWISLER, T.; CEBULA, R.P. Earth Probe Total Ozone Mapping Spectrometer (TOMS) data products user guide. NASA, Washington, DC, Tech. Rep. TP-1998-206895, 1998.

MARCHAND, M.; BEKKI, S.; PAZMINO, A.; LEFÈVRE, F.; GODIN-BEEKMANN, S.; HAUCHECORNE, A. Model simulations of the impact of the 2002 Antarctic ozone hole on midlatitudes. J. Atmos. Sci., v. 62, p. 871-884, 2005.

PERES, L. V.; KALL, E.; CRESPO, N.M.; FONTINELE, J.L.; ANABOR, V.; PINHEIRO, D.K.; SCHUCH, N.J.; LEME, N.M.P. Caracterização sinótica do evento de Efeito Secundário do Buraco de Ozônio Antártico sobre o Sul do Brasil do dia 14/10/2008. Ciência e Natura, Ed. Suplementar, Universidade Federal de Santa Maria, p. 323-326, 2011.

PERES, L.V.; REIS, N.C.S.; SANTOS, L.O.; BITTENCOURT, G.D.; SCHUCH, A.P.; ANABOR, V.; PINHEIRO, D.K.; SCHUCH, N.J.; LEME, N.M.P. Análise Atmosférica dos Eventos de Efeito Secundário do Buraco de Ozônio Antártico Sobre o Sul do Brasil em 2012. Parte 2: Verificação Sinótica da Troposfera Durante os Eventos. Ciência e Natura. v. 36, p. 423-433, 2014.

PERES, L.V.; REIS, N.C.S.; SANTOS, L.O.; BITTENCOURT, G.D.; SHUCH, A.P.; Anabor, V.; PINHEIRO, D.K.; SCHUCH, N.J.; LEME, N.P. Análise Atmosférica dos Eventos de Efeito Secundário do Buraco de Ozônio Antártico Sobre o Sul do Brasil em 2012. Parte 1: Identificação dos Eventos e Análise da Dinâmica da Estratosfera. Ciência e Natura, v. 38, p. 290-299, 2016.

PERES, L.V.; BENCHERIF, H.; MBATHA, N.; SCHUCH, A.P.; TOIHIR, A. M.; BÈGUE, N.; PORTAFAIX, T.; ANABOR, V.; PINHEIRO, D.K; LEME, N.M.P.; BAGESTON, J.V.; SCHUCH, N.J. Measurements of the total ozone column using a Brewer spectrophotometer and TOMS and OMI satellite instruments over the Southern Space Observatory in Brazil, Ann. Geophys., v. 35, p. 25-37, 2017.

PEREZ, A.; CRINO, E.; DE CARCER, I.A.; JAQUE, F. Lowozone events and three-dimensional transport at midlatitudes of South America during springs of 1996 and 1997. J. Geophys. Res-Atmos., v. 105, n. D4, p. 45534561, 2000.

PINHEIRO, D.K.; LEME, N.P.; Peres, L.V.; Kall, E. Influence of the antarctic ozone hole over South of Brazil in 2008 and 2009. National Institute of Science and Technology Antarctic Environmental Research, v. 1, p. 33-37, 2011.

PINHEIRO, D.K.; PERES, L.V.; CRESPO, N.M.; SCHUCH, N. J.; LEME, N.M.P. Influence of the Antarctic ozone hole over South of Brazil in 2010 and 2011. Annual Active Report 2011 - National Institute of Science and
Technology Antarctic Environmental Research, v. 1, p. 34-38, 2012.

PEREZ, A.; JAQUE, F. On the Antarctic origin of low ozone events at the South American continent during the springs of 1993 and 1994. Atmos. Environ., v. 32, n. 21, p. 36653668, 1998.

RANDEL, W.J.; WU, F. Isolation of the ozone QBO in SAGE II data by singular value decomposition, J. Atmos. Sci, v. 53, p. 2546-2559, 1996.

SALBY, M. L. Fundamentals of atmospheric physics. International geophysics series, v. 61, Academic Press, 1996.

SCHUCH, P.A.; SANTOS, M.B.; LIPINSKI, V.M.; PERES, L. V; SANTOS C.P.; CECHIN S.Z.; SCHUCH, N.J.; PINHEIRO, D.K.; LORETO, E.L.S. Identification of influential events concerning the Antarctic ozone hole over southern Brazil and the biological effects induced by UVB and UVA radiation in an endemic treefrog species. Ecotoxicology \& Environmental Safety: v. 118, p. 190-198, 2015.

SEMANE, N.; BENCHERIF, H.; MOREL, B.; HAUCHECORNE, A.; DIAB, R.D. An unusual stratospheric ozone decrease in Southern Hemisphere subtropics linked to isentropic air-mass transport as observed over Irene $\left(25.5^{\circ}\right.$ S, 28. $1^{\circ}$ E) in mid-May 2002. Atmos. Chem. Phys., v. 6, p. 1927-1936, 2006.

SOLOMON, S. Stratospheric ozone depletion: a review of concepts and history. Reviews of Geophysics, v. 37, n. 3, p. 275-316, 1999.

STEFFENEL, L.A.; PINHEIRO, M.K.; PINHEIRO, D.K.; PERES, L.V. Using a Pervasive Computing Environment to Identify Secondary Effects of the Antarctic Ozone Hole. Procedia Computer Science. , v.83, p.1007-1012, 2016.

VIATTE, C.; SCHNEIDER, M.; REDONDAS, A.; HASE, F.; EREMENKO, M.; CHELIN, P.; FLAUD, J. M.; BLUMENSTOCK, T.; ORPHAL, J. Comparison of groundbased FTIR and Brewer O3 total column with data from two different IASI algorithms and from OMI and GOME-2 satellite instruments, Atmos. Meas. Tech., v. 4, p. 535-546, 2011.

WAUGH, D. W. Subtropical stratospheric mixing linked to disturbances in the polar vortices. Nature, v. 365, p. 535-537, 1993.

World Meteorological Organization (WMO), Guide to Meteorological Instruments and Methods of Observation, 6th ed. Geneva, Switzerland: WMO, 1996. WMO Publication $\# 8$.

XIE, F.; LI, J. P.; TIAN, W. S.; ZHANG, J. K.; SHU. J. C. The impacts of two types of El Nĩno on global ozone variations in the last three decades. Adv. Atmos. Sci., v. 31, n. 5, p. 1113-126, 2014.

This is an Open Access article distributed under the terms of the Creative Commons Attribution License, which permits unrestricted use, distribution, and reproduction in any medium, provided the original work is properly cited. 